\title{
Repair strategy for housing stock engineering systems to improve energy efficiency
}

\author{
Ekaterina Plyusnina ${ }^{1}$ and Vera Akristiniy ${ }^{1, *}$ \\ ${ }^{1}$ Moscow State University of Civil Engineering, 129337, Moscow, Yaroslavskoe shosse, 26, Russia
}

\begin{abstract}
The article discusses problems of current interest concerning the housing and utility sector associated with increasing the level of comfort of living by constantly improving measures for carrying out planned and unscheduled repairs and surveys. This work provides a methodology for justifying the choice of a repair strategy for engineering systems of water supply and sewerage in the process of operating the housing stock, the implementation of which will contribute to the timely and rational repairs and inspections of buildings engineering systems. This will allow systematically eliminating engineering systems malfunctions, predicting and planning the optimal quantity and chronology of repair and restoration activities by maintaining the technical condition of the engineering system elements within the permissible limits during the standard service life.The main goal of the research in the presented material is to substantiate the methodology for choosing a repair strategy for water supply and sewerage systems during the operation of apartment buildings. The optimal periodicity for the repair of engineering systems depends on the failure rate of elements and the costs associated with the execution of all operational activities. Three options considered for organizing repairs of engineering equipment.Applied in actual practice the technique of choosing the repair strategy of engineering systems for selecting the optimal option to organize repairs of engineering equipment.
\end{abstract}

\section{Introduction}

Any housing stock can be viewed as a system, each element of which has its own service life. The influence of many random factors (the quality of construction and installation works and building materials, natural factors, etc.) on a building leads to the fact that structural elements and engineering systems have a service life of variable values that require methodological substantiation for optimal operation.

The constant provision of utilities to the housing stock is ensured by the work of the public utility companies. Operation of engineering systems - measures aimed at maintaining the operability and performance of the specified functions by cold and hot water supply systems and a water disposal system (sewerage). The working condition of the water supply and sewerage systems consists of the uninterrupted supply of water for household and drinking needs, for the fire extinguishing system, and the disposal of liquid municipal waste

*Corresponding author: 7824666@mail.ru 
into the city network, respectively. With an increase in the service life of engineering systems (ES), their reliability decreases, because the physical deterioration of the main elements of water supply systems increases.Pipelines that make up the bulk of engineering systems are prone to external corrosion of the pipe walls, a decrease in throughput due to the accumulation of substances on the inner walls of the pipes that impede the passage of water and liquid municipal waste. Shut-off valves, which include: ball valves, valves, measuring instruments, gate valves - are influenced by the climatic conditions of the room in which they are installed, the state of impermeability of the sealing seams, in the event of leakage, a strong effect of water will be exerted on the shut-off valves and the pipe. It is precise during operation that regular inspections and repairs are carried out to improve the reliability of the engineering systems.

To understand the current state of operation of the apartment buildings (AB) engineering systems, an online survey was conducted of 105 residents living in houses of different characteristics. During the analysis of the data, we obtained information (see Fig. 1-8) about the state of the water supply and sewerage systems.

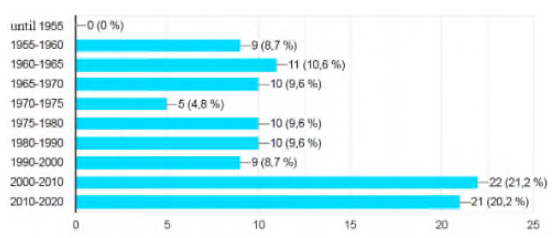

Fig.1. Diagram of AB commissioning period

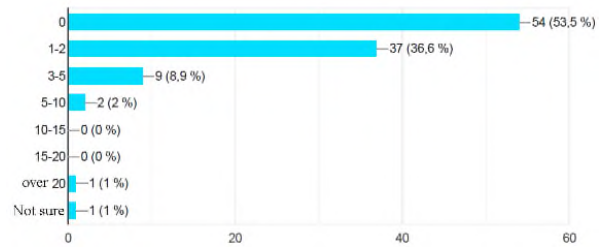

Fig.3.Diagram showing the number of incidents on the cold water supply system(CWS) of an AB during the period of inhabitation of a resident

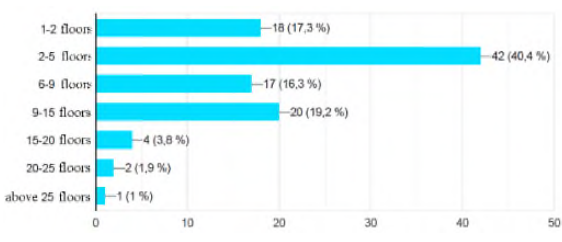

Fig.2.Diagram showing which floor a resident lives on

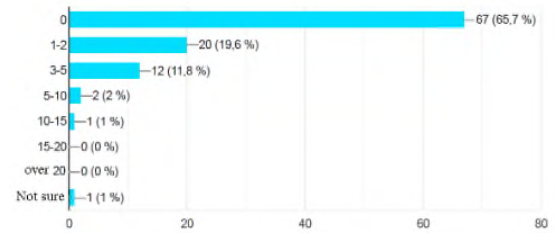

Fig.4.Diagram showing the number of incidents on the hot water supply system(HWS) of an AB during the period of inhabitation of a resident

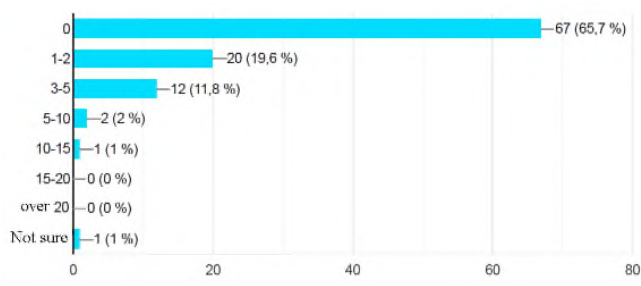

Fig.5.Diagram showing the number of incidents on the sewerage system of an AB during the period of inhabitation of a resident

The diagrams show that residents on average live below the 15 th floor, and $54 \%$ of residents did not have incidents with cold water supply system (CWS) during the period of inhabitance when $37 \%$ of residents experienced incidents. Up to two incidents on the hot water supply system (HWS) was present in $19.6 \%$ of residents, from two to five - in $11.8 \%$, and only $65.8 \%$ of residents had no problems with the system. On the sewerage system, $70 \%$ of residents did not have incidents, only $25 \%$ of residents had from one to five incidents on the system. 
Further research is aimed at reducing incidents on engineering systems by choosing a repair strategy.

\section{Literature review}

Improving the efficiency, reliability, and quality of the systems and facilities of public water supply and at the same time, the safety of their operation can be achieved by assessing and monitoring the reliability indicators of systems and equipment (shut-off valves, measuring instruments), as well as taking measures to determine the actual technical state of the supply and distribution water system, individual structures and equipment [1].

For the efficient operation of engineering systems (ES), it is required to carry out activities to organize the maintenance [2]. Thus during the operation of engineering systems (ES) conduct systematic inspections, monitor the correctness of the employees' work responsible for engineering facilities. Prompt adoption of organizational measures to restore efficiency or serviceability; coordinated performance of planned preventive works with adjacent divisions; accounting for failures in work. The system of planned preventive repairs of residential buildings is a set of measures for carrying out scheduled maintenanceand major repairs (see table 1), inspections of engineering systems with a certain frequency [3]. Failures and malfunctions in the operation of water supply systems [4] depend on the material, year of operation, and service life of the pipelines.

Table 1.The frequency of scheduled major repairs.

\begin{tabular}{|c|c|c|c|c|}
\hline \multirow{2}{*}{$\begin{array}{c}\text { Group of residential build- } \\
\text { ings on the degree of relia- } \\
\text { bility and durability of } \\
\text { buildings and structures }\end{array}$} & $\begin{array}{c}\text { Major repairs frequency, } \\
\text { years }\end{array}$ & \multicolumn{3}{|c|}{$\begin{array}{c}\text { Frequency of scheduled maintenance, } \\
\text { years, with a general deterioration of } \\
\text { the building,\% }\end{array}$} \\
\cline { 3 - 5 } & $18-21$ & upto 20 & $\begin{array}{c}\text { from 20 to } \\
30\end{array}$ & $\begin{array}{c}\text { from 30 to } \\
40\end{array}$ \\
\hline I, Ia & $12-15$ & $4-5$ & 4 & $3-4$ \\
\hline II, III, IIIa & $9-12$ & 4 & 3 & $3-4$ \\
\hline IV & & $4-5$ & 3 \\
\hline
\end{tabular}

Improving the efficiency of engineering systems (ES) depends on the activities of the management organizations of apartment buildings (AB) and resource-supplying organizations. Comparison by the author [5], [6] of the effectiveness of management various methods of apartment buildings $(\mathrm{AB})$ has shown that the greatest number of the rules and norms violations of technical operation, as well as complaints from residents, have management organizations. To advance the quality of the operating organizations' work and improve the technical condition of the housing stock, it is proposed to create an information system for monitoring the technical condition of the apartment building (AB) and the performance of the operating organizations, to increase the control efficiency, including public control, over their activities. Monitoring changes in the technical condition of residential buildings will allow solving social and economic problems in the management structure of housing and utility services, will contribute to the implementation in practice of the basic principles of the program-targeted approach to management.

The parametric model for determining the residual resources of engineering systems (RES) considered in [7] is the joint use of retrospective and current information about the observed object state trend and expert opinions on possible (indistinct) values of the boundaries of its limiting state. This approach improves the state of the system of maintenance and repair of buildings and structures as a whole.It allows for more effectively expanding the information base of decision-making on planning and executing the necessary manage- 
ment reaction on buildings and structures engineering equipment objects in comparison with the other known methods [8], [9].

\section{Materials and instruments}

The subject of the research is a methodology for substantiating the choice of a repair strategy for the object of research - water supply and sewerage systems. The purpose of the calculation is to achieve inequality (3), taking into account the limited time to restore the efficiency of its elements according to formula (2) and the economic feasibility of the decisions [10].

Speaking about the reliability of engineering systems, one should consider their general features, which are as follows:

1. the technological structure of the system is such that if any of its elements fail, the entire system or part of it fails;

2. the consequences of failure manifest themselves gradually or instantly, but in any case, the operational service has a certain reserve of time (limited) to restore the operability of the failed system element by repairing it, replacing it with a spare one, or putting a reserve into operation $-\Delta \mathrm{Z}_{\mathrm{L}}$. This time limit is determined:

- by objective factors (heat engineering characteristics of the building, climatic conditions, technical characteristics of equipment, etc.), which occurs in the event of a water supply and sewerage system failure;

- by subjective factors, i.e. the permissible level of discomfort for consumers in terms of depth and duration, which is typical for systems such as water supply;

3. the minimum duration of a failed i-th element in an inoperative state is determined by the recovery time of its operability according to formula 1 :

$$
\Delta Z_{r e c(i)}=\Delta Z_{r(i)}+\Delta Z_{f(i)}
$$

where $\Delta Z_{r(i)}$ - the time spent on disconnecting the element, repairing it or replacing it and putting it into operation (if there is a reserve, there are no repair or replacement costs, and the quantity $\Delta Z_{r(i)}$ has a minimum value, especially with the automatic introduction of a reserve); $\Delta Z_{f(i)}$ - time interval from the moment of failure of an element to the beginning of repair and restoration work[11-12].

Both components of the element recovery time are random values, and when analyzing the system reliability, we will take into account their mathematical expectations.

The recovery time depends, first, on the method of restoring operability and the availability of a reserve, as well as the maintainability of the system element, the qualifications of the repair personnel, and the equipment of the operational services with technical diagnostic tools. At the same time, the recovery of any element must be less than the time limit of inoperability of the entire system according to the formula 2 :

$$
\Delta Z_{\text {rec }(i)} \leq \Delta Z_{L}
$$

Technical measures that increase the reliability of the system include the reserve of elements or parts of the system, zoning of the system, as well as the localization of potential failures by means of the mechanism of disconnecting elements.However, the reservation of not all elements is technically possible, in this case it is necessary to look for ways to increase $\Delta Z_{L}$.If the effect of the proposed measures turns out to be insufficient, then the reliability of the entire system, determined by the frequency of failures $I_{(Z)}$, increases to the levelregulated by the social, sanitary, hygienic, and ecological requirements [1] to the environment $I_{f(Z)}^{\text {prop }}$. This is achieved by reducing the overhaul period (first for the elements with 
the highest failure rate, and then for the remaining elements), the overall reliability of the entire system increases until the desired result is obtained according to formula 3 :

$$
I_{\mathrm{OT}(Z)} \leq I_{f(Z)}^{\text {prop }},
$$

The fulfillment of condition (3) is necessary in case of impossibility of satisfying the requirement (2), however, it demands an economic justification [13,14].

The optimal period for repairs of elements of water supply and sewerage systems is such a time interval at which the following conditions are met:

- the element failure rate should not exceed the maximum permissible value;

- the costs associated with the implementation of all operational measures and the element exploitation during the period between repairs must be economically justified.

The failure rate of an element depends on its inherent properties, on the procedure and frequency of repairs. Consider 3 options for organizing repairs of engineering equipment:

1.System of Planned Repair Periodicity (PRP) - at the appointed time, strictly periodically, major repairs of the elements is conducted, leading to a complete restoration of operational properties (replacement or complete renewal). Failures occurring during the period between repairs are eliminated by the emergency dispatch service within the established time frame (see Fig. 6).

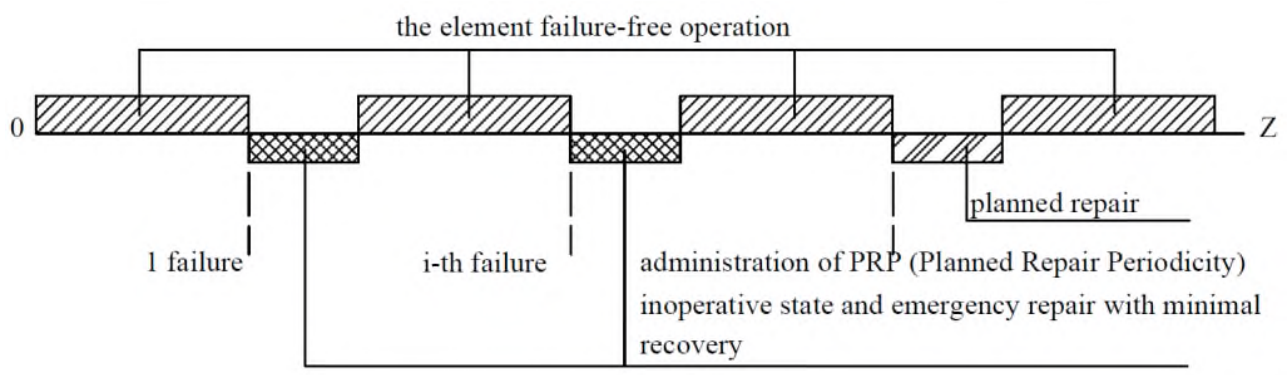

Fig. 6. Organization chart PRP repairs.

The formula 4 define the failure rate:

$$
I_{f}=\frac{\pi \cdot Z_{p}}{4 \cdot Z_{a v}^{2}}
$$

where $Z_{p}$ - the assigned frequency of planned repairs (determined by the operational organization); $Z_{a v}$-average element operation span.

2.System of planned and emergency repairs with full recovery (see Fig. 7).

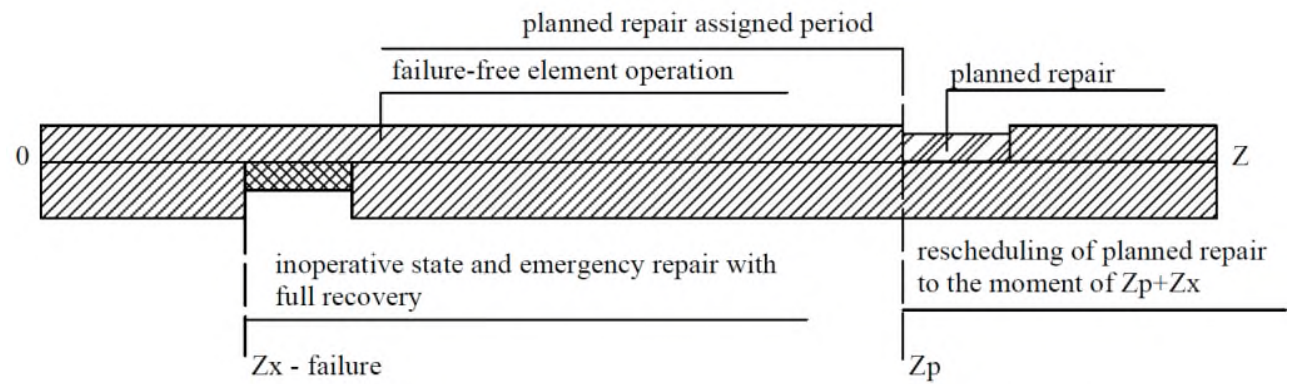

Fig.7.Cart of planned and emergency repairs with full recovery. 
As in the first organization variant, a period of planned repairs is assigned. However, if a failure occurs in the period between scheduled repairs, the element is fully repaired. After the elimination of the failure, the deadline for the next planned repair is rescheduled.Such an organization of operation increases the level of reliability of elements and reduces losses caused by replacing the structure before the expiration of the standard period of its depreciation. However, the implementation of such a system is associated with the complexity of performed work accounting [15]. The failure rate is determined by formula 5 :

$$
I_{f}=\frac{\mathrm{A}}{Z_{a v}}
$$

whereA - coefficient depending on the ratio of the planned repair period to the average element operation span $Z_{a v}$.

3.Inspection system - repair of elements based on the results of their periodic inspections. At the designated time periods, the element is inspected and, if signs of failure (limiting state) are found, the structure is repaired (see Fig. 8).

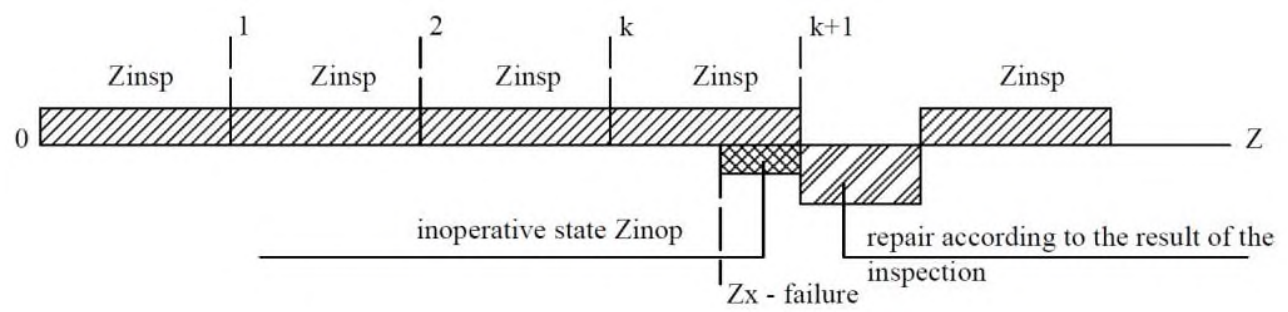

Fig.8.Scheme of the repairs organization based on the results of inspections.

Formula 6 determine the failure rate:

$$
I_{f}=\frac{1}{Z_{a v} \cdot D}
$$

where $D$ - coefficient depending on the ratio of the inspection periodicity to the element average operation $\operatorname{span} Z_{a v}$.

Such an indicator as the time that an element is in an inoperative state characterizes the inspection system, along with the failure rate.Formula 7 determine the duration of an inoperative state, depending on the frequency of inspections:

$$
Z_{a v}^{\text {inop }}=\mathrm{E} \cdot Z_{a v}
$$

where $E$ - coefficient depending on the ratio of the inspection periodicity to the average service span of the element $Z_{a v}$.

4.If the system element has been reserved, the failure rate of reserve group is determined by the formula 8 :

$$
I_{f}=\frac{I^{r e s}}{Z_{a v}}
$$

where $I^{r e s}$ - the frequency of failures of the entire reserve group, determined depending on the ratio of the repair periodicity to the average service span of the element.

We introduce a new coefficient to clarify the value of the failure rate Kps - the coefficient of the physical state of engineering systems, is determined by formula 9:

$$
K_{p s}=\frac{Z_{\text {fact }}}{Z_{\text {stan }}}
$$


where $Z_{\text {fact }}$ - given service life of an element of engineering equipment, years; $Z_{\text {stan }}$ - standard service span of an element of engineering equipment, years.

Therefore we have $I_{f}^{\text {total }}$, the total failure rate is:

$$
I_{f}^{\text {total }}=I_{f}+K_{p s}
$$

Before the start of determining the options for organizing repairs of engineering equipment, the service span of these system elements is determined and table 2 is compiled, determining the type of material and the volume of engineering systems in accordance with the data of the operating organization and technical inspections. The adjusted service span of the element $Z_{a v}^{a d j u s t}$, years, is determined by the formula 11 :

$$
Z_{a v}^{a d j u s t}=Z_{a v}+Z,
$$

wherez - period of time, depending on the material (for a more accurate service span, you can check the service spanprovided by the manufacturer), years.

\begin{tabular}{|c|c|c|c|c|c|c|}
\hline № & Elementname & Material & Unitmeasurements & Volume & $\begin{array}{l}\text { Average ser- } \\
\text { vice span of the } \\
\text { element to the } \\
\text { onset of the } \\
\text { limiting state } \\
Z_{\text {av(i), years }}\end{array}$ & $\begin{array}{c}\text { The adjusted } \\
\text { service span } \\
\text { of the ele- } \\
\text { ment } \\
Z_{a v}^{a j u s t} \text {, years }\end{array}$ \\
\hline 1 & 2 & 3 & 4 & 5 & 6 & 7 \\
\hline 1 & Pipeline & Metal & runningmetre & 100 & 40 & 45 \\
\hline$\ldots$ & $\ldots$ & $\ldots$ & $\ldots$ & $\ldots$ & $\ldots$ & $\ldots$ \\
\hline
\end{tabular}

Table 2.The service span of the engineering equipment elements of the system.

For comparison, several options for organizing operation are selected (see Table 3) for each element of water supply and sewerage, the data of which are summarized in Table 4, based on the data of technical inspection of engineering systems.

Table 3. Variants of the operation method of engineering systems.

\begin{tabular}{|l|c|}
\hline \multicolumn{1}{|c|}{ Operationvariantname } & $\begin{array}{c}\text { Limiting failure } \\
\text { rate }_{f}^{\text {lim }}, \text { year }^{-1}\end{array}$ \\
\hline $\begin{array}{l}\text { Allowable values of water temperature rise in the pipeline of } \\
\text { the Hot Water Supply(HWS) system, } \mathrm{t}_{\text {op }}{ }^{\circ} \mathrm{C}\end{array}$ \\
at $60^{\circ} \mathrm{C}$ & 1 \\
at $70^{\circ} \mathrm{C}$ & 1 \\
at $80^{\circ} \mathrm{C}$ & 0.98 \\
at $95{ }^{\circ} \mathrm{C}$ & 0.5 \\
\hline Permissible values of the increase in water temperature in the & \\
pipeline of the cold water system, top $^{\circ} \mathrm{C}$ & \\
at $20^{\circ} \mathrm{C}$ & \\
\hline Permissible values of the reduction in throughput in the sew- & \\
erage system pipeline depending on the wastewater flow rate & 1 \\
$Q \mathrm{~m}^{3} / \mathrm{s}$ & 0.95 \\
by $0.5 \%$ & 0.93 \\
by $1 \%$ & 0.9 \\
by $1.5 \%$ & 0.8 \\
more than $1.5 \%$ & \\
\hline
\end{tabular}


Table 4.Optimization of a repair strategy for engineering systems.

\begin{tabular}{|c|c|c|c|c|c|}
\hline № & $\begin{array}{c}\text { Systemelemen } \\
\mathrm{t}\end{array}$ & $\begin{array}{l}\text { Method } \\
\text { of op- } \\
\text { eration } \\
\text { (several } \\
\text { options) }\end{array}$ & $\begin{array}{l}\text { Periodbetween- } \\
\text { repairs,years }\end{array}$ & $\begin{array}{c}\text { The adjusted } \\
\text { service span of } \\
\text { the ele- } \\
\text { ment } Z_{a v}^{a d j u s t} \\
\text { years }\end{array}$ & $\begin{array}{c}\text { Estimatedfailurerat } \\
\mathrm{e}\end{array}$ \\
\hline 1 & 1 & 2 & 3 & 4 & 5 \\
\hline 1 & Pipeline & $20^{0} \mathrm{C}$ & 3 & 25 & 0.029 \\
\hline$\ldots$ & $\ldots$ & $\ldots$ & $\ldots$ &. & $\ldots$ \\
\hline
\end{tabular}

The failure rates of elements are calculated for the selected operation methods according to formulas 3-7 and are compared with the limiting values of failure rates at permissible values of hot water temperature and sewerage capacity.

The calculation is carried out until the condition is $\operatorname{met} I_{f(z)} \leq I_{f(z)}^{l i m}$, which is achieved by, firstly, reservation of elements for which it is technically possible, secondly, we change the repair organization schemes, thirdly, by gradually reducing the period between repairs $\left(\mathrm{Z}_{\mathrm{pl}}\right)$ at the beginning for elements with the highest failure rate, and then for the rest elements [16-17].

\section{Study results}

The study collected the following data:

1. Management company LLC "Second House Management", located in Russia, Moscow region, town. Nakhabino, st.Shkolnaya, 13 - has in its operation 20 residential buildings with a total living area of $132112,05 \mathrm{~m}^{2}[18,19]$, the data on which are given in table 5 .

2. We carry out the calculation according to the first option using the formula (4).

Registry of houses operated by LLC "Second management houses":

\begin{tabular}{|c|c|l|}
\hline Yearbuilt & Numberofstoreys & \multicolumn{1}{c|}{ Buildingaddress } \\
\hline 2002 & 9 & St.11 Saperov, 2 \\
\hline $2005-2007$ & $10-17$ & St.Inzhenernaya, 5; St.Shkolnaya, 8, 11, 15; St.Novaya, 8 \\
\hline 2014 & $4-5$ & $\begin{array}{l}\text { St.Sadovaya, 8, 10, 12, 14; St.Shirokaya, 11, 13, 15, 17, 19, } \\
21 \text {; St.Ryabinovaya, 1, 7, 11 building 1, 13 }\end{array}$ \\
\hline
\end{tabular}

Classifying residential buildings by year of construction in the period from the $2000 \mathrm{~s}$ to 2010, which already have a long service life of engineering systems, we will consider the first six houses.

Table 5.Registry of housing in the operation of "second homes Management".

\begin{tabular}{|c|l|c|c|c|c|}
\hline № & \multicolumn{1}{|c|}{ Adress } & $\begin{array}{c}\text { Totallivingar } \\
\text { ea, } \mathrm{m}^{2}\end{array}$ & $\begin{array}{c}\text { Numbe } \\
\text { rofstor } \\
\text { eys }\end{array}$ & $\begin{array}{c}\text { Numbero } \\
\text { frooms }\end{array}$ & a briefdescription \\
\hline 1 & St.11 Saperov, 2 & 4293.1 & 9 & 108 & Year built-2002 \\
\hline 2 & St.Shkolnaya, 5 & 3962.6 & 10 & 78 & Yearbuilt- 2005 \\
\hline 3 & St.Shkolnaya, 8 & 18176.6 & 12 & 313 & Year built-2005 \\
\hline 4 & St.Shkolnaya, 11 & 21655.0 & 14 & 362 & Year built-2006 \\
\hline 5 & St.Shkolnaya, 15 & 7899.9 & 17 & 136 & Year built-2006 \\
\hline 6 & St. Novaya, 8 & 32461.1 & 17 & 533 & Year built-2007 \\
\hline
\end{tabular}


The results of justifying the choice of the repair strategy are presented on the basis of the diagrams of the results obtained according to the calculations of the adjusted service span of the elements and are systematized element by element in Table 7(see Fig. 9).

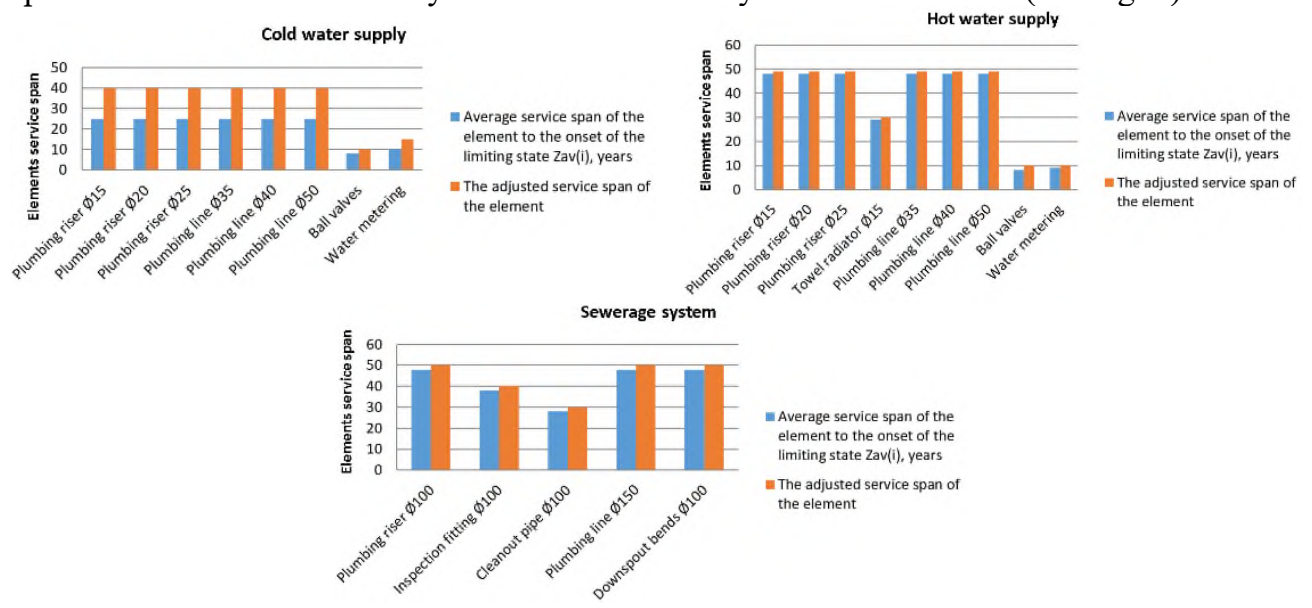

Fig.9.The diagrams of the results obtained according to the calculations of the adjusted service span of the elements.

The total failure rate $I_{f}^{\text {total }}$, s calculated for the average period of operation as $(18+15+15+14+14+13) / 6=14,83$ years. The operating option is selected according to Table 3 based on the data of the managing organization.

Table 6.Optimization of a repair strategy for engineering systems.

\begin{tabular}{|c|c|c|c|c|c|c|}
\hline № & $\begin{array}{c}\text { Systemelem } \\
\text { ent }\end{array}$ & $\begin{array}{c}\text { Methodofoperat } \\
\text { ion }\end{array}$ & $\begin{array}{c}\text { Periodbetweenrepa } \\
\text { irs, years }\end{array}$ & $\begin{array}{l}\text { The } \\
\text { adjust- } \\
\text { ed } \\
\text { service } \\
\text { span } \\
\text { of the } \\
\text { ele- } \\
\text { ment } \\
Z_{\text {av }}^{\text {adjust }} \\
\text {, years }\end{array}$ & $\begin{array}{l}\text { Estimatedfailurer } \\
\text { ate }\end{array}$ & $\begin{array}{l}\text { The } \\
\text { total } \\
\text { failure } \\
\text { rate } \\
I_{f}^{\text {total }}\end{array}$ \\
\hline 1 & 1 & 2 & 3 & 4 & 5 & 6 \\
\hline & \multicolumn{6}{|c|}{ Coldwatersupply } \\
\hline 1 & $\begin{array}{l}\text { Plumbingris } \\
\text { er Ø15 }\end{array}$ & at $20^{\circ} \mathrm{C}$ & 15 & 40 & 0.029 & 0.623 \\
\hline 2 & $\begin{array}{l}\text { Plumbingris } \\
\text { er Ø20 }\end{array}$ & at $20^{\circ} \mathrm{C}$ & 15 & 40 & 0.029 & 0.623 \\
\hline 3 & $\begin{array}{l}\text { Plumbingris } \\
\text { er Ø25 }\end{array}$ & at $20^{\circ} \mathrm{C}$ & 10 & 40 & 0.020 & 0.613 \\
\hline 4 & $\begin{array}{l}\text { Plumbinglin } \\
\text { e Ø35 }\end{array}$ & at $20^{\circ} \mathrm{C}$ & 10 & 40 & 0.020 & 0.613 \\
\hline 5 & $\begin{array}{l}\text { Plumbinglin } \\
\text { e Ø40 }\end{array}$ & at $20^{\circ} \mathrm{C}$ & 10 & 40 & 0.020 & 0.613 \\
\hline 6 & $\begin{array}{l}\text { Plumbinglin } \\
\text { e Ø50 }\end{array}$ & at $20^{\circ} \mathrm{C}$ & 10 & 40 & 0.020 & 0.613 \\
\hline 7 & $\begin{array}{l}\text { Standartport } \\
\text { bore ball }\end{array}$ & at $20^{\circ} \mathrm{C}$ & 8 & 10 & 0.251 & 2.105 \\
\hline
\end{tabular}




\begin{tabular}{|c|l|c|c|c|c|c|}
\hline 8 & valves & & & & \\
\hline 8 & $\begin{array}{l}\text { General- } \\
\text { purpose } \\
\text { water meter- } \\
\text { ing EKO-20 }\end{array}$ & at20 ${ }^{\circ} \mathrm{C}$ & 8 & 15 & 0.112 & 1.595 \\
\hline
\end{tabular}

The total failure rate is less than the limiting failure rate, the condition $I_{f}^{\text {total }}<I_{f(Z)}^{\text {lim }}$ is fulfilled in all cases except for the values for the ball valve and the water metering. With a decrease in the period between repairs, the failure rate will decrease(see Fig. 10).

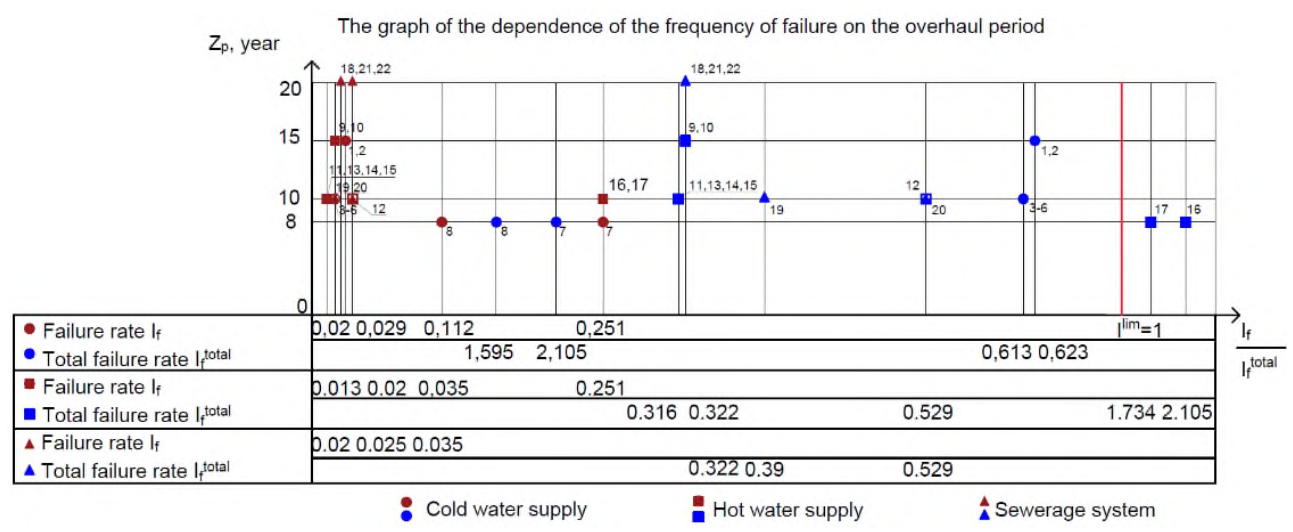

Fig. 10.The graph of the dependence of the frequency of failure on the overhaul period.

\section{Conclusion}

When operating the engineering systems of the housing stock, it is important at the commissioning stage to determine the optimal method for choosing a repair strategy for engineering systems due to the constant wear and tear of equipment, which is of a probabilistic nature of occurrence, depending on various factors [20,21].

In the work, the methodology for choosing a repair strategy for engineering systems of water supply, sewerage and heating systems was applied during the operation of residential apartment buildings [22]. Taking into account the service span of engineering systems, the defined choice of the periodicity between repairs based on the practical results of determining the required indicators for the optimal characteristics for individual engineering systems. The practical application of the technique made it possible to determine the most favorable chronology for carrying out repair and restoration measures of engineering systems.

\section{References}

1. SR 30.13330.2016 Internal water supply and sewerage of buildings

2. Manual for the technical operation of buildings, structures, engineering systems and technical means "Izvestia",276 (Moscow,FGUP Publishing House, 2017)

3. L. Shubin, O. Datyuk, Yu. Konovich. Examples of calculations for the organization and management of the operation of buildings.Study guide for universities,280(Moscow,Stroyizdat, 1991)

4. M. Zaharevich, A. Kim, A. Martyanova. Improving the reliability of water supply systems through the introduction of safe forms of organization of their operation and construction: training manual,62 (SPbGASU,Saint-Petersburg,2011) 
5. Analysis of the efficiency of management of apartment buildings on the example of Voronezh.

Housingandutilitiesinfrastructure,3(6)(2018)https://elibrary.ru/item.asp?id=35396265 (Last accessed 12.01.2021)

6. M. Lebed, M. Dementeva, Modern problems and trends in housing management. Housingandutilitiesinfrastructure,4(15), 106-113 (2020)

7. T. Soldatenko,Model of the residual life of engineering systems with a high level of wear, Civil Engineering magazine, 6 (2012)

8. V. Utkin, L. Utkin,Expert method for determining the physical wear of buildings.Industrial and civil engineering, 1, 48 (2000)

9. V. Sokolov. Building a solution for assessing the technical condition of structural systems of buildings and structures using probabilistic recognition methods.Civil Engineering magazine, 6, 48-57 (2010)

10. O. Datyuk, N. Umnyakova. Methodological guidelines for the development of a course project on the discipline "Technical operation of buildings", 39 (Moscow,MGSU,2003)

11. "Housing and Utilities Reform" https://www.reformagkh.ru (Last accessed 15.01.2021)

12. Y. Kolyhaeva. Procedia - Social and Behavioral Sciences, 166, 557-561 (2015)

13. P.Sampaio, R.Sampaio,Utilities Policy,64, 101049 (2020)

14. S. Krishnan,International Journal of Disaster Risk Reduction,35, 101061 (2019)

15. F. Papagiannis, P.Gazzola,O.Burak, I.Pokutsa,Journal of Cleaner Production,183, 358-369 (2018)

16. H. Hashim, P. Ryan, E. Clifford,Advanced Engineering Informatics,46, 101187 (2020)

17. M. Alsaydalani,Journal of Water Supply: Research and Technology - Aqua, 66(5), 327-339 (2020)

18. D. Rojas, K. Vargas, A. Cortes, S. Rocha,Journal of Pipeline Systems Engineering and Practice, 11(4) (2020)

19. Q. Sui, F. Wei, X. Lin, Z. Li,International Journal of Electrical Power \& Energy Systems, 125, 106445 (2021)

20. Y. Chen, J. Li, H. Lu, P. Yan,Journal of Cleaner Production,278, 123209 (2021)

21. J.Xiong, J. Zhu, Y. He,Sustainable Cities and Society,60, 102267 (2020)

22. J.D'Amelio,Mechanical Estimating Manual: Sheet Metal, Piping and Plumbing,318 (2021) 